Address for Correspondence: Dr. Pi-xin Ran,

The Key State Laboratory of Respiratory Disease, Guangzhou Institute of Respiratory Diseases, the First Affiliated Hospital of Guangzhou Medical University, Guangzhou 510120 , Guangdong Province, China

E-mail:13902233092@139.com

\begin{tabular}{|l|}
\hline Access this article online \\
\hline $\begin{array}{l}\text { Website: } \\
\text { www.intern-med.com }\end{array}$ \\
\hline $\begin{array}{l}\text { DOI: } \\
\text { 10.1515/jim-2015-0012 }\end{array}$ \\
\hline Quick Response Code: \\
\hline \\
\\
\\
\hline
\end{tabular}

\section{Clinical characteristics of tobacco smoke-induced versus biomass fuel- induced chronic obstructive pulmonary disease}

\author{
Lin-ling Cheng', Ya-ya Liu' ${ }^{2}$, Zhu-quan Su${ }^{1}$, Jun Liư ${ }^{1}$, \\ Rong-chang Chen ${ }^{1}$, Pi-xin Ran ${ }^{1}$
}

${ }^{1}$ The Key State Laboratory of Respiratory Disease, Guangzhou Institute of Respiratory Diseases, the First Affiliated Hospital of Guangzhou Medical University, Guangzhou 510120, Guangdong Province, China;

${ }^{2}$ Guangzhou Profession College of Foods and Drugs, Guangzhou 510120, Guangdong Province, China

\section{ABSTRACT}

Objective: To investigate differences in clinical features between tobacco smoke-induced and biomass fuel-induced chronic obstructive pulmonary disease (COPD). Methods: We retrospectively analyzed 206 patients with COPD caused by exposure to tobacco smoke and 81 cases of COPD caused by exposure to biomass fuels who received treatment in our hospital between 2011 March and 2014 March. Difference in general health status, clinical symptoms, the dyspnea score, and comorbidities between the two groups were compared. In addition, pulmonary function, grading, and acute exacerbations were also compared. Results: (1) Difference in general health status: Male and female patients with COPD caused by exposure to tobacco smoke were 83.5 and $16.5 \%$, respectively. Male and female patients with COPD caused by exposure to smoke from biomass fuels were 14.8 and $85.2 \%$ $\left(X^{2}=27.2, P<0.05\right)$, respectively. Tobacco smoke-induced COPD was more prevalent in men, and COPD caused by exposure to smoke from biomass fuels was more prevalent in women. After gender adjustment, body mass index (BMI) was lower in women with COPD caused by exposure to smoke from biomass fuels than those by tobacco smoke. There was no statistically significant difference in other indicators, such as age. (2): Difference in clinical symptoms: No statistically significant difference in the modified British Medical Research Counsel (mMRC) Questionnaire, a measure of breathlessness, was observed between the two groups. Dyspnea was more common in COPD patients that was caused by exposure to biomass fuels (38.3\%) than by tobacco smoke $(11.1 \%)\left(X^{2}=17.9, P<0.05\right)$. The comorbidities of allergic diseases (such as allergic rhinitis, bronchial asthma) were more prevalent in COPD patients that was caused by exposure to smoke from biomass fuels $(43.2 \%)$ than by tobacco smoke $(18 \%)$ $\left(X^{2}=16.1, P<0.05\right)$. However, COPD comorbid with lung cancer was more prevalent in those cases that were caused by exposure to tobacco smoke $(7.77 \%)$ than in cases caused by exposure to smoke from biomass fuels $(3.7 \%)\left(x^{2}=9.7, P<0.05\right)$. (3) Differences in grading of pulmonary function: After gender adjustment, patients with COPD caused by exposure to biomass fuels were mostly in grade B or D. (4) Exacerbations: No significant difference in exacerbations per year was noted between the two groups. Conclusions: Marked differences exist between patients with COPD caused by exposure to tobacco smoke and smoke from biomass fuels. Patients with COPD caused by exposure to biofuels are mostly females with lower BMI and often with many clinical symptoms and complications, such as allergic rhinitis and bronchial asthma. Such patients are often in stage B or D. Tobacco smoke-induced COPD is more prevalent in male patients, often with complications in the form of lung cancer.

Key words: chronic obstructive pulmonary disease; smoking; biomass fuels; clinical characteristics 


\section{INTRODUCTION}

Cigarette smoking is the most dangerous risk factor for chronic obstructive pulmonary disease (COPD $)^{[1]}$ and appropriately $90 \%$ of COPD patients are smokers or exsmokers $^{[2-4]}$. However, some people who develop COPD are non-smokers ${ }^{[5-7]}$. In recent years, in rural areas, the impacts and role of biomass fuels in the pathogenesis of COPD have received increasing attention. Biomass fuels refer to firewood, woods, charcoal, crop residues, and animal dung. The main harmful components of such smoke are oxycarbide, oxynitride, oxysulfide, incompletely burned hydrocarbon particles, and multicyclic organic compounds ${ }^{[8]}$. Evidence-based medicine indicates that exposure to smoke from biomass fuels is also an important risk factor for the pathogenesis of COPD. Currently, the clinical features of biomass fuel-induced COPD, especially the difference between COPD caused by exposure to smoke from biomass fuels and COPD by cigarette smoking in particular, is not clear. Our research discusses in detail the clinical characteristics of tobacco smoke-induced versus biomass fuel-induced COPD.

\section{PATIENTS AND METHODS}

\section{Clinical data}

We gathered 287 COPD patients at Guangzhou Respiratory Disease Research Institution from 2011 March to 2013 March. Among them, there were 206 smoke-induced COPD patients (hereafter Group A) with an average age of $59 \pm 7$ and 81 biomass fuel-induced COPD patients (hereafter Group B) with an average age of $63 \pm 9$. The inclusion criteria for Group A included both a history of 20 or more pack-years of smoking and the diagnostic criteria of 2011 COPD guide. The inclusion criteria for Group $\mathrm{B}$ included a history of exposure to smoke from biomass fuels for an average of at least 30 minutes per day for more than 5 years, and the diagnostic criteria of 2011 COPD guide. According to the guide, after the administration of bronchodilators, diagnostic criteria of 2011 COPD guide were the $\mathrm{FEV}_{1} / \mathrm{FVC}<70 \%$ and $\mathrm{FEV}_{1} /$ predicted value $<80 \%$. Both groups excluded patients with a history of exposure to both smoke and smoke from biomass fuels. All patients provided written informed consent. The study was approved by the relevant ethics.

\section{Clinical observation}

A clinical observation was conducted for (1) shortness of breath and dyspnea, which were assessed by using the Modified Britain Medical Research Counsel Questionnaire(mMRC) (2) other respiratory symptoms, such as coughing and panting (3) cardiovascular symptoms or signs (coronary heart disease and pulmonary heart disease) such as precordial squeezing pain, edema affecting lower extremities, and bulbar conjunctiva (4) assessment of comorbid conditions: comorbid with other respiratory diseases, that is, bronchial asthma, allergic rhinitis, bronchiectasis, and other cardiovascular diseases. Diagnostic criteria of COPD comorbid with bronchial asthma (also bronchial asthma-COPD overlapping syndrome) required that: (1) the patient had paroxysmal panting and wheezing of both lungs during expiratory phase (2) the patient was a long-term smoker (3) the patient's lung function was tested at entry and after 1-week anti-asthma treatment of anti-inflammatory spasmolysis. Both lung functions were $\mathrm{FEV}_{1} / \mathrm{FVC}<70 \%$ and the improvement of after-treatment was $\geq 12 \%$ and the absolute value was $\geq 200 \mathrm{ml}$.

\section{Pulmonary function test and COPD classification}

We used the MasterScreen lung function tester (Germany Jaeger) to test vital capacity (VC), FVC, $\mathrm{FEV}_{1} / \mathrm{FVC}$, peak expiratory flow (PEF), maximum mid-expiratory flow (MMEF75/25), total lung capacity (TLC), and residual volume (RV). All the measuring indices were repeatedly measured three times and only the maximums were used. Based on the 2011 edition GOLD guide and according to the following three factors: dyspnea ratings, lung function classification, and acute exacerbation risk, we classified all COPD patients into grades A, B, C, and D.

\section{Acute exacerbations}

Acute exacerbations were defined as acute worsening of symptoms, that is, coughing, expectoration, shortness of breath, or panting and consequently, required altered treatment plan. The acute exacerbations of both groups within the previous year were recorded.

\section{Statistical analysis}

All the measurement data accorded with the normal distribution was expressed as Mean \pm Standard deviation. Comparison between groups used $t$ test. The difference was statistically significant when $P<0.05$.

\section{RESULTS}

\section{General health status}

Differences in general health status between two groups: subjects in Group A were mostly male $(83.5 \%, 172 / 206)$, while subjects in Group B were mostly female $(85.2 \%$, 69/81). The gender difference was statistically significant $\left(\chi^{2}=27.2, P<0.05\right)$. After gender adjustment, the body mass index (BMI) of Group B patients was lower than that of Group A. No statistically significant differences in other indices were observed between the two groups, such as age and baseline lung function (Table 1). 
Cheng et al.: Clinical characteristics of tobacco smoke-induced versus biomass fuel-induced chronic obstructive pulmonary disease

\begin{tabular}{|c|c|c|c|}
\hline & age & BMI & $\mathrm{FEV}_{1} /$ predicted \\
\hline \multicolumn{4}{|c|}{ Smoke-induced COPD (206) } \\
\hline Male(172) & $60 \pm 7$ & $19.4 \pm 5.6$ & $52.6 \pm 9.3$ \\
\hline Female (34) & $58 \pm 9$ & $16.6 \pm 4.8$ & $50.4 \pm 7.9$ \\
\hline \multicolumn{4}{|c|}{ Biomass fuel-induced COPD (81) } \\
\hline Male (12) & $61 \pm 11$ & $16.1 \pm 3.6^{*}$ & $50.9 \pm 4.8$ \\
\hline Female (69) & $64 \pm 7$ & $13.7 \pm 5.2^{*}$ & $47.8 \pm 6.7$ \\
\hline
\end{tabular}

*Note: Compared with biomass fuel-induced COPD of the same gender. BMI: body mass index.

\section{Clinical symptoms}

As for the difference in clinical symptoms between the two groups, after gender adjustment, the difference in mMRC between the two groups was not statistically significant. In this regard, men in Group A scored $3.2 \pm 1.3$ and women scored $2.7 \pm 0.6$ while men in Group B scored $3.7 \pm 0.9$ and women scored 2.9 \pm 1.1. Patients in Group B showed more panting than those in Group A, which were 38.3\% (31/81) and $11.1 \%(23 / 206)$, respectively $\left(\chi^{2}=17.9, P<0.05\right)$. However, the incidence of coughing was similar for both groups $(72.8 v$ s. $79.6 \%)$. The difference in comorbidities of cardiovascular events (coronary heart disease, arrhythmia, left heart failure, etc.) between Group A and Group B was not statistically significant, $\left(14.8 v\right.$ s. $12.6 \%, \chi^{2}=1.4, P>$ $0.05)$. The ratio of patients comorbid with allergic diseases (such as allergic rhinitis and bronchial asthma) in Group B was higher than that of Group A, which were 43.2 and $18 \%\left(\chi^{2}=16.1, P<0.05\right)$, respectively. However, the ratio of the patients comorbid with lung cancer in Group A was higher than that of Group B, which were 7.77 and $3.7 \%$ $\left(\chi^{2}=9.7, P<0.05\right)$, respectively. No significant difference in comorbidities of bronchiectasis and chronic pulmonary heart diseases between Group A and B was observed (5.83 vs. $6.17 \% ; 36.9$ vs. $39.5 \%$ ).

\section{Pulmonary function}

As for the classification of pulmonary function, in Group A, 40 male patients were classified as Grade B and 49 as Grade D, taking up $51.7 \%$ of the male smoking group. Totally, 7 female patients were classified as Grade B and 9 as Grade D, taking up $47 \%$ of the female smoking group. In Group B, 5 male patients were classified as Grade B and 4 as Grade D, taking up $75 \%$ of the male smoking group. Totally, 27 female patients were classified as Grade B and 23 as Grade D, taking up $72.5 \%$ of the female smoking group. In terms of COPD classification, after gender adjustment, compared with Group A, patients in Group B were mostly Grade B and D and showed more symptoms.

\section{Difference in acute exacerbations}

The acute exacerbation frequency of patients in Group B and Group A were $0.9 \pm 0.3$ and $1.2 \pm 0.5$, respectively, and no statistical difference was observed $(t=2.4, P>0.05)$.

\section{DISCUSSION}

COPD is a systemic and chronic inflammatory disease associated with lungs' abnormal inflammatory response to noxious gases or particles such as tobacco smoke $e^{[9]}$.Currently, tobacco smoking is considered as the main pathogenic factor for COPD, while recently, the role of smoke from biomass fuels in the pathogenesis of COPD has been emphasized. Increasing evidence indicates that, in developing countries, smoke from biomass fuels is the main source of indoor air pollution and also an important risk factor for the pathogenesis of COPD. Our research investigated the differences in clinical features between COPD caused by exposure to tobacco smoke and smoke from biomass fuels. Our findings indicate that COPD caused by exposure to smoke from biomass fuels are mostly seen in women with the presence of lower BMI and more clinical symptoms, and the comorbidities are mostly allergic rhinitis and bronchial asthma and the COPD classification are mostly Grades B and D. In addition, COPD caused by tobacco smoke is mostly seen in men and its comorbidity is mostly lung cancer.

Incompletely burned biomass fuels release large amounts of polluted gases such as methanol, sulfur dioxide, and carbon monoxide, especially the sulfocompound ${ }^{[10-11]}$. Consequently, once such smoke is inhaled into the body, it will lead to airway inflammation, airway injury, and continuous non-specific bronchial hyper-responsiveness ${ }^{[12]}$. Previous researches have shown that biofuel smoke could lead to bronchial mucosa goblet cell metaplasia and excessive mucus secretion, as well as an obvious increase in the number of eosinophils in phlegm and neutrophils and eosinophils in bronchial walls and bronchoalveolar lavage fluid (BALF), resulting in an increased airway inflammatory response during acute exacerbations in COPD ${ }^{[13-18]}$. Clinically, coughing, expectoration, and panting are more likely to ensue. This also explains our findings that biofuel-induced COPD patients tend to have more cough, expectoration, and panting with comorbidities of mostly allergic rhinitis and bronchial asthma ${ }^{[19]}$.

Cigarette smoke contains large amounts of cancerogenic substances such as tar, benzopyrene, nitrosamine, arsenic, 
and cadmium. Research has shown that the degree of DNA injury was more severe in patients with COPD caused by exposure to cigarette smoke than by exposure to smoke from biomass fuels. Further research in this regard has shown that the DNA injury degree is positively associated with the concentration of malondialdehyde ${ }^{[19-20]}$. For patients with COPD caused by exposure to either cigarette smoke or biofuel smoke, oxidative stress markers and DNA injury degree in particular, are increased. Because DNA injury is directly related to cell canceration, it also, to some extent, explains why the rate of lung cancer is higher in patients with COPD caused by long-term smoking than COPD caused by exposure to smoke from biomass fuels ${ }^{[21]}$.

Moreover, our research also observed that patients with COPD caused by exposure to biofuels are mostly women. Among the female COPD patients, the BMI was lower in the patients with COPD of the same age group caused by exposure to smoke from biomass fuels than those by exposure to tobacco smoke. This, possibly, is related to the fact that women in rural areas of our country have more chances and longer time of contact with biofuels than men do. COPD patients generally suffer from malnutrition and skeletal muscle atrophy of different degrees, and there are relatively worse economic and social conditions for patients living in rural areas. This might be the reason why patients with COPD caused by exposure to smoke from biomass fuels tend to have lower BMI ${ }^{[22-26]}$.

To sum up, our research preliminarily observed the clinical feature difference between patients with COPD caused by exposure to tobacco smoke and smoke from biomass fuels and revealed the clinical feature of different COPD phenotypes (smoking-caused or biomass fuel-caused) and provided new theoretical basis for future prevention and clinical treatment of these subtypes pertinently.

\section{Acknowledgement}

The study is funded by the Natural Science Foundation of Guangdong Province, China.

\section{Conflicts of Interest}

None declared.

\section{REFERENCES}

1. Sethi JM, Rochester CL. Smoking and chronic obstructive pulmonary disease. Clin Chest Med 2000; 21:67-86.

2. Liu LY, Zeng M, Xie CM, Gao JH, Yan YS, Lu GF, et al. Oxidative stress status in patients with chronic obstructive pulmonary disease and its relation to glucocorticoid receptor levels. J South Med Univ 2008; 28: 992-6.

3. Li WF. Risk factors for chronic obstructive pulmonary disease: A Casecontrol study. J South Med Univ 2010; 30: 2009-10, 2012.
4. Zhou X. Advances in diagnosis and treatment of acute exacerbations of chronic obstructive pulmonary disease. Shanghai Med J 2007; 30: 649-51.

5. Bascom R. Differential susceptibility to tobacco smoke: possible mechanism. Pharmacogenetics 1991; 1:102-6.

6. Snider GL. Chronic obstructive pulmonary disease: risk factors, pathophysiology and pathogenesis. Annu Rev Med 1989; 40: 411-29.

7. Molfino NA, Coyle AJ. Gene-environment interactions in chronic obstructive pulmonary disesase. Int J Chron Obstruct Pulmon Dis 2000; 3:491-7.

8. Ran PX. Unigorable effects of biofuels in the pathogenesis of chronic obstructive pulmonary disease. Chin J Tuberculosis Respir Dis 2010; 33: 241-2.

9. Torres-Duque C, Maldonado D, Perez Padilla R, Ezzati M, Viegi G. Biomass fuels and respiratory diseases: a review of the evidence. Proc Am Thorac Soc 2008; 5: 557-90.

10. Global Strategy for the diagnosis, management, and prevention of COPD (updated 2014). Global Initiative for Chronic Obstructive Lung Disease. www.goldcopd.org. Accessed on March 5, 2014.

11. Viegi G, Simoni M, Scognamiglio A, Baldacci S, Pistelli F, Carrozzi L, et al. Indoor air pollution and airway disease. Int J Tuberc Lung Dis 2004; 8: 1401-15.

12. Ezzati M, Kammen DM. The health impacts of exposure to indoor air population from solid fuels in developing countries: knowledge, gaps and data needs. Environ Health Perspect 2002; 110: 1057-68.

13. Mattsen JD, Haus BM, Desai B, Ott W, Basham B, Agrawal M, et al. Enhanced acute responses in an experimental exposure model to biomass smoke inhalation in chronic obstructive pulmonary disease. Exp Lung Res 2008; 34: 631-62.

14. Liu CY, Xu LJ, Duan XM.. Relationship between Human Cytomegalovirus Infection in Patients with Chronic Obstructive Pulmonary Disease and Cell-mediated Immune. J Jilin Univ (Med Edition) 2003; 29: 439-41.

15. Gu YH, Ouyang Y, Sun DS. Effects of CCL20 antibody on expression of surface factors of DCs in peripheral blood and BALF of rats with COPD. J Jilin Univ (Med Edition) 2013; 39: 236-40.

16. Mou Y, Jiang CY. The clinical significance of detection serum sICAM-1, inflammatory mediators levels of patients with chronic obstructive pulmonary disease. J Clin Med Pract 2014: 18: 28-31.

17. Feng QQ, Xia XZ. Expressions of Bach1 and $\gamma$-GCS in lung tissue of patients with chronic obstructive pulmonary disease. J Zhengzhou Univ (Med Edition) 2013; 4: 474-6, 477.

18. Wei K, Zhou YN. Changes of serum IL-18 level in patients of chronic obstructive pulmonary disease with acute exacerbation before and after the treatment and its significance. J Guiyang Med College 2009; 34: 65961.

19. Saetta S, Di Stefano A, Maestrelli P, Turato G, Mapp CE, Pieno M, et al. Airway eosinophilia and expression of interleukin- 5 protein in asthma and in exacerbations of chronic bronchitis. Clin Exp Allergy 2006; 26: 766-74

20. Li ZJ, Han WQ, Pan Y, Liu JW, Zhu YJ, Yao YH, et al. Investigation on smoking status and smoking-harm cognitive degree among adults in Jilin province. J Jilin Univ (Med Edition) 2013; 39: 1288-93.

21. Wang W, Hao CF, Wu YJ, Wu YM. Effects of p53 Arg/Pro gene polymorphism and smoking on the occurrence of lung cancer in Henan Han population. J Zhengzhou Univ (Med Edition) 2010; 45: 746-8.

22. Wang WM, Cui L, Zhuang $\mathrm{Y}, \mathrm{Wu} \mathrm{LC}, \mathrm{Xu} \mathrm{XH}$. Advances in chronic obstructive pulmonary disease combined with anxiety and depression. J Clin Med Pract 2014; 18:191-4.

23. Wang MH, Miao QL, Mo LY. Application of nutrition support therapy in treatment of elderly patients with chronic obstructive pulmonary disease. J Clinical Med Pract 2013; 17: 41-4.

24. Sun J, Zheng JJ, Guo SW, Zhu Z, Chen X. Application of Mini Nutritional Assessment in patients with chronic obstructive pulmonary disease and its correlation with BODE indexes. J South Med Univ 2013; 33: 1217-20.

25. Ying SC, Zhou XD, Zhou LH, Hu X, Liu YQ. Effect of exercise combined with encouragement on quality of life of patients with chronic obstructive pulmonary disease. J South Med Univ 2013; 33: 1312-5

26. Wu RX, Kuang JL. Research progress in clinical phenotypes of chronic obstructive pulmonary disease. Med J Chin PLA 2013; 38: 519-23.

How to cite this article: Cheng $L$, et al. Clinical characteristics of tobacco smoke-induced versus biomass fuelinduced chronic obstructive pulmonary disease. J Transl Intern Med 2015;3:126-129 